Article

\title{
Sustainable Ageing: Supporting Healthy Ageing and Independence Amongst Older Turkish Migrants in the UK
}

\author{
Melisa Yazdanpanahi ${ }^{1}$ and Shereen Hussein ${ }^{2, *}$ \\ 1 The Urban Institute, School of Energy, Geoscience, Infrastructure and Society, Heriot-Watt University, \\ Edinburgh EH14 4AS, UK; my8@hw.ac.uk \\ 2 Department of Health Services Research and Policy, Faculty of Public Health and Policy, London School of \\ Hygiene and Tropical Medicine, Keppel Street, London WC1E 7HT, UK \\ * Correspondence: shereen.hussein@lshtm.ac.uk
}

Citation: Yazdanpanahi, M.; Hussein, S. Sustainable Ageing: Supporting Healthy Ageing and Independence Amongst Older Turkish Migrants in the UK. Sustainability 2021, 13, 10387. https://doi.org/10.3390/ su131810387

Academic Editor: Laurie Buys

Received: 7 August 2021

Accepted: 15 September 2021

Published: 17 September 2021

Publisher's Note: MDPI stays neutral with regard to jurisdictional claims in published maps and institutional affiliations.

Copyright: (c) 2021 by the authors. Licensee MDPI, Basel, Switzerland. This article is an open access article distributed under the terms and conditions of the Creative Commons Attribution (CC BY) license (https:// creativecommons.org/licenses/by/ $4.0 /)$.

\begin{abstract}
In the UK, as in many other European countries, the population is growing older, and older adults are becoming more diverse. As a result, there is a mounting interest in supporting healthy ageing and independence, acknowledging the needs and agency of older adults from diverse backgrounds, expectations, and life trajectories. Healthy ageing is promoted as a critical component of sustainable ageing to ensure meaningful social and economic contributions through the life course for all individuals. However, the definitions of healthy ageing are debatable. The public and policy discourse treat all older adults through generic and homogeneous models that do not consider the heterogeneity of experiences and perspectives of old age among different groups. In this context, independence has often been defined in terms of functional independence, i.e., cognitive and physical functioning, as a core construct of healthy ageing. However, this focus excludes older adults' interpretations and day-to-day experiences of this concept. This article investigates the interpretation and lived experience of independence amongst older Turkish adults in the UK as a central explanatory concept of healthy ageing. Semi-structured individual interviews $(n=48)$ and community mapping workshops $(\mathrm{n}=5)$ were conducted with 65 older Turkish adults in London, supplemented by interviews with professional service providers $(n=13)$ within the community. The data collection was conducted between March and November 2017. We identified three main themes integral to understanding healthy ageing and independence: 1-interdependency and having reciprocal care relations; 2-individual autonomy at home and choice in housing options; and 3-functional independence, mobility, and control over the physical environment. Independence appears to remain an essential element of healthy ageing. However, it is a fluid and complex construct constantly negotiated around personal and community resources. Therefore, there is a need to develop more comprehensive interventions that capture the diverse experiences in old age to enable healthy ageing and social sustainability. These are timely considering current policy directions such as the UN Decade of Healthy Ageing and the 2030 Sustainable Development Goals.
\end{abstract}

Keywords: independence; healthy ageing; ethnic minority older adults; Sustainable Development Goals; care relations; mobility; age-friendly environments

\section{Introduction}

Population ageing is a global phenomenon occurring in countries at various levels of development. The global share of older people (aged 65 years or over) increased from 6 per cent in 1990 to 9 per cent in 2019 as a proportion of the world population, and is projected to exceed 16 per cent by 2050 [1]. Surrounding the ageing demographics, there often exist negative attitudes towards ageing in public and policy discourse which have stigmatised old age as a period of weakness and decline [2]. This has been termed 'apocalyptic demography' and the 'ageing time bomb', where older adults are often regarded as a malevolent force that is going to overwhelm society [3]. In recent decades, there have been 
attempts to shift the focus of debate from negative aspects of old age, such as perceived economic burden, towards positive views of human ageing that value older adults as economic and social assets [4]. This new paradigm of ageing has led to the emergence of terms such as 'successful', 'active', and 'healthy' ageing both in the policy sphere and academic discourse of positive ageing [5-7]. These efforts have culminated with the launch of the United Nation's Decade of Healthy Ageing 2021-2030, aligned with the last 10 years of the Sustainable Development Goals [8]. The decade focuses on four specific action areas of age-friendly environments, ageism, integrated care, and long-term care.

The definitions of healthy ageing are broad and range from biological aspects such as the absence of morbidity to social and psychological dimensions such as personal autonomy, social participation, and feelings of wellbeing [9]. In some research, healthy ageing has been used interchangeably with successful ageing $[10,11]$; in this sense, the definition of healthy ageing has been closer to the biomedical models of ageing, which emphasise maintenance of functional independence [9]. Indeed, the World Health Organisation's (WHO) definition of healthy ageing revolves around the functional ability to enable wellbeing in old age [12]. Functional independence is often measured in terms of bodily function and cognitive and physical capabilities [13], evident in the academic definitions of successful ageing. Functional independence is seen as a binary construct by many researchers, e.g., $[14,15]$, creating two groups of dependent/unsuccessful or independent/successful ageing processes [16,17], perpetuating current inequalities in ageing [18].

This over-emphasis on functional independence can be observed in the policy rhetoric of successful ageing in more economically developed countries, which has promoted a desired image of a self-reliant and independent older adult responsible for their own care $[5,19,20]$. This has created a culture of 'defence against dependence' in most western developed societies in which independence is a cherished value and dependency is a state to be avoided [21,22]. In this cultural context, older adults are often blamed for a failure to avoid disability and maintain independence [23,24]. However, research shows that maintaining physical functioning is directly related to socioeconomic status and environmental factors over the life course [25], which are out of the control of many older adults. For example, maintaining physical functioning and independence is a less plausible goal to achieve for older adults from poorer segments of the society due to lifetime factors such as poor physical health, low wages, and physically demanding and insecure employment, among other factors, that lead to lower levels of physical and financial capabilities in old age [22].

The WHO, in its latest World Report on Ageing and Health, defines healthy ageing as 'the process of developing and maintaining the functional ability that enables well-being in older age $e^{\prime}$ [26] (p. 28). The report underlines that functioning is not only determined by the physical health level of individuals but also by the interactions of individuals with the environments they inhabit across their lives [26]. In the same report, environments are stated to include 'home, community and broader society, and all the factors within them such as the built environment, people and their relationships, attitudes and values, health and social policies, the systems that support them and the services that they implement' [26] (pp. 28-29). This holistic definition shows the recognition of the social and community aspects of healthy ageing and potentially shifts the responsibility from the individual to maintain functional independence and improve personal situations to enabling physical and social environments that support the values of healthy ageing [22]. In this sense, it invites a shift in defining independence towards other determinants than just functional independence, such as older people's agency, control, and choice [27-31]. The latter would encompass social, community, and environmental factors that increase options and choices to age well among older adults. The important role of enabling environments in older adults' journey to healthy ageing was also reinforced in the recent United Nations (UN) decade of healthy ageing. Acknowledging the 'diversity in the capacity and circumstances of older adults' and mutual relationships between older adults and their environments, with age-friendly policies emphasising the necessity of responding to diversity in needs and preferences, fa- 
cilitating choice and valuing older adults' decisions, reducing inequalities, and supporting vulnerable groups [8].

For minority ethnic communities, the paths to healthy ageing and independence are further shaped by many other factors. Previous research has shown that ethnic minority older adults have lower levels of wellbeing compared to the white majority population in the UK [32,33]. Language barriers [34], different norms and attitudes towards care in old age [35], material deprivation, and structural barriers [36] are some of factors hindering the access to supports for healthy ageing amongst older, ethnic minority adults.

A few studies conducted with the Turkish community in the UK reported high levels of social isolation [37], lack of English language skills [38], difficulties in access to services, and lack of information and awareness $[37,39]$ among older members of the community. In addition, unlike many other ethnic communities of the UK who have a longer history of settlement in the country, the majority of the older members of the Turkish community are first-generation migrants to the UK (especially older adults from mainland Turkey), experiencing ageing in a foreign land; therefore, their experiences of healthy ageing are distinctive from other ethnic minority older adults who are second- or third-generation descendants of pioneer migrants to the UK.

The aim of this article is to investigate the interpretation and lived experience of independence amongst older Turkish adults in the UK as a main explanatory concept of healthy ageing. To achieve this aim, the following objectives were considered:

- To explore how the concept of independence is articulated within the context of healthy ageing by older Turkish adults in the UK.

- To explore the role of personal and community resources in shaping the experience of healthy ageing and independence amongst older, ethnic minority Turkish adults.

- To examine the barriers and facilitators to healthy ageing and independence amongst older, ethnic minority Turkish adults.

\section{Methods}

An interpretive qualitative case study approach guided the research design and methodology. We conducted 48 semi-structured individual interviews with older Turkish adults, 13 semi-structured individual interviews with professional service providers, and five community mapping workshops with 17 members of the community in London. The semi-structured design of the interviews and community mapping workshops allowed participants to reflect on their experiences in their own words [40] while also ensuring that key research areas were being addressed. Community mapping workshops can be described as 'a focus group around a map' [41] that aims to understand experiences of the physical environment of a particular place by its residents through community dialogue over a map of that place [41] (p. 10). We further conducted community mapping workshops as a complementary technique to individual interviews in this research to capture the socio-spatial dimensions of older Turkish adults' experience of ageing in London, shared feelings, and collective construction of meanings around healthy ageing and independence. Community mapping workshops were designed to explore participants' interactions with the physical, social and service environment of their living area. Workshops involved participants depicting their living environments and identifying the assets and deficits of their residential area in supporting healthy ageing and independence using sticker notes and pens, followed by a collective conversation around aspects of ageing in their local area.

The sample chosen for inclusion in the study included older Turkish adults who have aged in the UK or those who have arrived to the UK in old age. The inclusion criteria for the study were those participants who were 50 years old and above and who self-identified as Turkish or where Turkish was their first or second language and lived in the capital, London. In the majority of research involving older adults, the minimum age considered for inclusion in the research is 60 years old, e.g., [42,43]. The rationale for including those less than 60 years old in this study was: (i) the early retirement age in Turkey of 50; (ii) beliefs around the start of old age among the community which is lower 
than western societies [44]; and (iii) the significant number of people in this age group (50-60) in the UK who will comprise the next generation of older Turkish adults in the UK, where understanding their needs for healthy ageing is important [45].

The rationale for selecting London was, firstly, the existence of a more visible Turkish community with concentrated and identifiable ethnic facilities and associations in comparison with other British cities, which could be used as initial contacts and gatekeepers to reach potential participants. Secondly, the absolute number of Turkish older adults in London and their more varied migration trajectories make it more feasible to reach a diverse sample of participants.

Interview guides for semi-structured individual interviews and community mapping workshops were used during the data collection. Due to the semi-structured design of the interview agendas for both individual interviews and community mapping workshops, general questions were asked, such as:

- Tell me about your attitudes towards becoming old.

- What are your likes and dislikes about your community?

- $\quad$ Take me through your typical day.

Guiding the interview discussion was the order and type of questions and prompts, which differed between the interviews and workshop discussions. However, we made sure that critical topics such as conceptualisation of healthy ageing, understandings of housing and home, family and care relations, accessibility and navigation of health and social care services, and barriers and opportunities to accessing the community were addressed.

The fieldwork was conducted between March and December 2017. Before starting the fieldwork, ethical approval was obtained from the University Research Ethics Committee. During the recruitment process and later in presenting the data, ethical issues relating to informed consent, voluntary participation, right to withdraw, and protection of privacy and anonymity were handled carefully to ensure that participants were not put at unnecessary risk by taking part in the research.

Most of the interviews and all community mapping workshops took place in Turkish/Kurdish associations located in north London, mainly in Hackney, Edmonton, and Enfield boroughs of London. Ten interviews were conducted out of associations in community venues such as places of worship, cafes, restaurants, and private homes of participants.

We used several recruitment methods, including desk-based research, approaching gatekeepers, recruiting via fliers, and face-to-face interaction in public places, and snowball sampling techniques to reach the desired sample size with the required levels of diversity representing the different groups of the Turkish community in London. However, the main method of recruiting participants involved contacting local community groups and associations due to the lack of collaboration outside of these organisations with the researchers. In the first instance, Turkish/Kurdish associations and community organisations in London were identified from desk-based research and coordinators or staff in charge were contacted to seek permission to participate in and be informed of events and activities targeting older adults. The first author frequently visited community centres, associations, and communal places in north London to make contact with the community. After recruiting older adults, a snowball sampling approach was used to recruit more participants. The second stage involved interviewing professional service providers for the community, including the management board of Turkish/Kurdish associations. Reaching data saturation has been the benchmark for determining the number of individual interviews and community mapping workshops with older Turkish adults to achieve the aim and objectives of the research. The data collection continued until the research team arrived at a consensus on the adequacy of data for answering the research questions and the emergence of no additional new themes from the interviews and workshops. After this point, two additional semi-structured individual interviews with older Turkish adults recruited from a new community centre in north London were conducted to ensure the accuracy of this decision. Nevertheless, the authors acknowledge limitations of the research in geographical confinement of the study to north London due to higher concentration of the community in this area and 
reliance of the research on community organisations for the recruitment of participants where the majority of interviews took place. Thus, the study failed to capture viewpoints of other older Turkish adults residing in central and south London who may have different socioeconomic positions. In addition, majority of the interviewees were ageing at their own home; thus, the study failed to capture viewpoints of more frail older Turkish adults residing in assisted living facilities/sheltered housing or nursing homes.

Individual interviewees lasted between 20 and 50 (average: 32) minutes, and the length of the five workshops varied from 45 to $67 \mathrm{~min}$ (average: $57 \mathrm{~min}$ ). All interviews were conducted by the first author in the Turkish language. Recorded interviews were transcribed verbatim, then professionally translated to English. A similar process was followed for community mapping workshops.

The average age of participants in the individual interviews was 64 years. The same information is not available for community mapping workshops since the interview agenda did not include private questions such as the age of participants. Among the 65 participants in both individual interviews and community mapping workshops, 16 had Cypriot origin, two were born and raised in London, and the majority $(n=47)$ originated from mainland Turkey. Among the last group, 25 people had migrated from the Kurdish regions of Turkey. The number of female participants was higher than male participants ( 43 vs. 22) since most interviews were conducted in Turkish/Kurdish associations, which are more popular with older female Turkish adults. A total of 16 of the male participants and 21 of the female participants were married at the time of the interviews and living with other family members, while the rest were living alone. The majority of participants in the semi-structured individual interviews had graduated from high school or elementary and primary school in Turkey, with a few being illiterate or having academic degrees. The same information is not available for the community mapping workshops due to the concerns around confidentiality and privacy of participants and the fact that asking these questions in a group setting would make participants feel uncomfortable. In terms of occupation, a considerable number of female participants in the semi-structured individual interviews were housewives with fewer numbers having worked as tailors in the textile industry in their early times of arrival to the UK. Food sector was the second-highest in terms of employment of the female respondents. Two participants had worked in both the food and textile sectors. A small number of participants were employed by their husbands or other relatives in their family businesses, usually restaurants or convenience stores. Only four female respondents had worked outside of the textile industry or restaurants, in British retail businesses as store cashiers or store supervisors. Male participants' occupations followed a similar pattern as female respondents, as the majority were employed in the textile industry in the early years of migration to the UK, followed by the food industry and the transportation sector in later years of life that in two cases extended to retirement years. Three male respondents had been employed in businesses other than the food and textile industries or transportation. This information is not available for participants in the community mapping workshops due to the concerns around confidentiality mentioned before. Table 1 provides a breakdown of participatns by key characteristics. 
Table 1. Characteristics of participants in the research.

\begin{tabular}{|c|c|c|c|c|c|c|c|c|c|c|}
\hline & \multirow{2}{*}{$\begin{array}{l}\text { Number of } \\
\text { Participants }\end{array}$} & \multirow{2}{*}{ Age } & \multicolumn{2}{|c|}{ Gender } & \multicolumn{2}{|c|}{ Place of Origin } & \multirow{2}{*}{$\begin{array}{l}\text { Number of } \\
\text { Years in the UK }\end{array}$} & \multirow{2}{*}{ Education Level } & \multicolumn{2}{|c|}{ Occupation } \\
\hline & & & Female & Male & Cyprus & Turkey & & & Female & Male \\
\hline $\begin{array}{l}\text { Individual } \\
\text { interviews }\end{array}$ & 48 & $\begin{array}{c}\text { Min: } 48 \\
\text { Max: } 87 \\
\text { Mean: } 64 \\
\text { Median: } 63\end{array}$ & 32 & 16 & 14 & 32 & $\begin{array}{c}\text { Min:5 } \\
\text { Max: } 65 \\
\text { Mean: } 28.23 \\
\text { Median: } 25\end{array}$ & $\begin{array}{l}\text { High school } \\
\text { grautes: } 23 \\
\text { Elementary and } \\
\text { primary school } \\
\text { graduates: } 15 \\
\text { Academic degree } \\
\text { holders: } 2 \\
\text { Illiterate: } 8\end{array}$ & $\begin{array}{l}\text { Textile: } 9 \\
\text { Food: } 8 \\
\text { Combination of } \\
\text { both: } 2 \\
\text { Housewives: } 13 \\
\text { Other: } 4\end{array}$ & $\begin{array}{c}\text { Textile: } 7 \\
\text { Food: } 5 \\
\text { Combination of } \\
\text { both: } 2 \\
\text { Transportation: } 3 \\
\text { Other:3 }\end{array}$ \\
\hline $\begin{array}{l}\text { Community } \\
\text { mapping } \\
\text { workshops }\end{array}$ & 17 & - & 11 & 6 & 2 & 15 & $\begin{array}{c}\text { Min: } 3 \\
\text { Max: } 48 \\
\text { Mean: } 33.88 \\
\text { Median: } 27\end{array}$ & - & & \\
\hline
\end{tabular}


Braun and Clarke's six-stage model of thematic analysis [46] was applied to classify the data and extract themes or patterns from the transcripts of interviews and community mapping workshops. The first stage, 'familiarisation with the data', started from the early stages of data collection when conducting the interviews and developing field notes. Indepth familiarity with the data was achieved through transcribing the audio records by the first author and reading and re-reading the transcripts. A set of codes were developed after full transcription and detailed analysis of the data. To ensure rigor, several transcripts were analysed separately by the second author and the supervisory team at Heriot-Watt University to develop a coding framework. The adjusted coding framework was applied to the rest of transcripts by the first author. Searching for themes involved sorting the different codes into potential sub-themes and themes. An inductive approach to theme development was adopted to allow full reflection of participants' experiences [47]. The final stages, 'reviewing themes', involved combining, separating, and renaming sub-themes and themes during multiple group meetings. Through a literature review, a deductive approach complemented developing these themes [46].

It is worth noting that transcripts from individual interviews and community mapping workshops were kept in separate databases, and the process of thematic analysis was applied separately to each group. However, community mapping workshops did not generate different data from individual interviews and many shared themes were identified at the initial stages of analysis. Since the number of transcripts from individual interviews with older Turkish adults (48) outweighed the number of community mapping workshops (5) with some strong themes being identified in the individual interviews, the structure of the final reporting of data analysis was based on the themes generated by the individual interviews, complemented by evidence derived from data generated through the community mapping workshops. In addition, the data obtained from individual semistructured interviews with professional service providers for the community were also analysed separately. They were used to support the themes or provide further insights into them.

\section{Findings}

The analysis revealed that older Turkish adults' assessment of their status in regards to healthy ageing was generally positive; however, the collected evidence from participants showed diversity in the understandings and interpretations of the concepts of healthy ageing and independence and their multi-dimensional nature. Findings identified that the concept of independence underpinned older Turkish migrants' understanding of healthy ageing. For older Turkish migrants to achieve healthy ageing, independence was found to be constructed through three interrelated facets: 1 -interdependency and having reciprocal care relations; 2-individual autonomy at home and choice in housing options; and 3functional independence, mobility, and control over the physical environment (Figure 1). These elements are explored in detail concerning the overarching concept of independence as a critical component of healthy ageing.

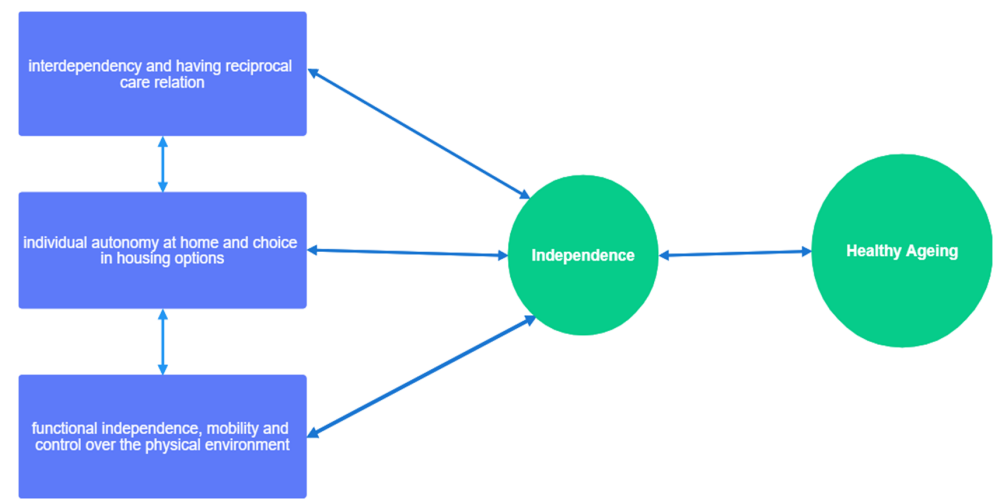

Figure 1. Older Turkish adults' understanding of healthy ageing. 


\subsection{Interdependency and Having Reciprocal Care Relations}

Important in understanding the interpretation of independence amongst the Turkish community was the process of negotiating independence within social relations and their role as informal sources of support available in old age. The social relations of older Turkish adults are primarily comprised of family members (spouses/partners, children, and grandchildren) followed by relatives and then neighbours. Family and relatives had a critical role in all stages of participants' life trajectories, starting from the motivations for the act of migration and assistance and support at the early stages of migration to adaptation to the host society and caregiving and emotional support in old age.

Intergenerational support from children and grandchildren, especially after the loss of a spouse, become an important source of support for migrants at old age. For most interviewees, children and grandchildren were the only reasons keeping them in the UK despite their desire to age in Turkey and Cyprus:

'Turkey is nice but I do not have anyone there. My children are living here, so inevitably

I have to live here.'

(Male, 85 years old, living alone, Mainland Turkey, 27 years in the UK.)

The above quote is also an indicator of the crucial influence of family in all aspects of Turkish older adults' lives, including their future migration decisions and residential arrangements in old age- - the fact that choosing a location in old age was not 'voluntary' but dependent on the choice of family members.

Although living close to offspring was frequently mentioned as the only reason for staying in the UK and, in some cases, for receiving help with their daily tasks (instrumental support) and emotional support, many participants did not expect their offspring to provide care at old age. Independence in old age and not relying on other people's help, including offspring in daily tasks, was a strong desire for the majority of participants:

'I do not know who will look after me in the future. The only thing is that I do not want to be a burden on my children. They will get married sooner or later. I do not want to create problems for them or distress them. I hope that I will never find myself in that situation. I pray to God to not make me dependent. I hope God will never make me needy of my children or anyone else.'

(Male, 66 years old, married, Mainland Turkey, 36 years in the UK.)

Although emotional dependency and frequently visiting their children and grandchildren were highly valued by interviewees, functional dependency on children and asking for help in carrying out day-to-day activities such as shopping, visiting a doctor, and similar tasks were being consciously avoided as much as possible:

'Conversations made in my appointments are very important. When I go alone, I cannot understand it. They get angry and say that your problems are very important. Bring a translator. There is a need for someone to come along with you all the time. I cannot ask my children to come with me all the time to appointments. They are both studying and working...'

(Female, 55 years old, living alone, Mainland Turkey, 26 years in London.)

However, despite the expressed desire for independence, dependency levels on children were unusually high among participants due to practical reasons such as the lack of English language proficiency and limited familiarity with the rules and regulations of the British health and care systems. For example, when engaging with healthcare providers, many participants relied on family and friends as translators. Such dependency extended beyond health and care into broader social and functional activities that involved interaction with British society. For example, some participants were dependent on their children for recreational activities and daily or monthly shopping and mobility in general. This dependency led to feelings of being a 'burden' amongst participants. Furthermore, while many were receiving help from their children with their daily tasks, most participants were unsure about the availability of their children in later life. 
Changing relationships inside the family as a result of migration, divorce and family breakdown, intergenerational conflicts, and increased globalisation and relocation of children to other places to find jobs or start their own families were some of the causes of uncertainty among participants when it came to the availability of familial care in later life. Cultural differences between Turkey and the UK in terms of family relationships and levels of adaptation to the host society among generations within the family were identified as key factors in explaining intergenerational tensions within the Turkish community in London by professional interviewees:

'Intergenerational conflict is high. They have some problems with the younger generation, because their cultural expectations from the younger generation are different from that of the British society. But attitudes and behaviour of people who have been born and raised here are different. For example, in case of respect, in our culture, we call everyone with "abla" and "abi" words. You cannot call anyone with his/her first name even if he/she is one year older than you. But here people call each other by their first name even if he/she is 20 years older than him. It sometimes creates problems for us in case of respect...' (Chief Executive Officer of a Turkish/Kurdish association.)

Attitudes towards care are highly diverse among the community. We found that older Turkish adults with stronger religious and traditional beliefs to be more likely to expect filial piety from their children based on the Islamic values. Besides religious factors, other factors such as time of arrival to the UK and migration origin (for example, arriving from rural or urban areas of Turkey) were also influential in participants' attitudes towards care. Adherence to Turkish family traditions and obligations was stronger among Kurds and Turks from mainland Turkey who had a shorter history of settlement in the UK compared to other groups, such as Turkish Cypriots, who arrived earlier to the UK. In traditional families, there is a negative attitude towards formal care with a strong stigma of the institutionalisation of older family members where younger members are available and capable of providing informal care to their elderly:

'I expect my children to look after me in my old age. They are very good; I am sure they will look after me. I hope God place kindness in their hearts. If God grants them kindness and love for Islam, they will look after me.'

(Female, 60 years old, married, Mainland Turkey, 28 years in the UK.)

'No, I do not expect my children to provide care to me. I rely on the government. I rely on myself. I am sure that I will be able to look after myself. My mother is 76 and looks after herself.'

(Female, 58 years old, married, Cyprus, 22 years in the UK.)

Despite these cultural differences, almost all participants preferred familial care to formal care in terms of the perceived quality of care received and anticipated relationships with the caregiver. However, acknowledging the different attitudes of the younger generations and considering the emotional and material costs of caregiving that can disrupt their children's daily life, paid care given by family members was preferred to care received by strangers. The latter is facilitated by cash-for-care schemes such as personal budgets in the UK. In all cases where family or friends were available for caregiving, older adults had requested the council to use their personal budget to assign these family members as their paid caregivers:

'My daughter-in-law is my caregiver. Now she is pregnant ... I do not want to bother her. I look after myself. I do not like strangers to look after me. I do not know them. Since I live alone, I am afraid. I cannot rely on anybody.'

(Female, 55 years old, living alone, Mainland Turkey, 26 years in the UK.)

However, the efficiency of this system is controversial. As the quotes above indicate, burdensome feelings still exist when a family member is assigned as a formal caregiver of older Turkish adults. Emotional relationships between a caregiver and recipient, in 
some cases, interrupted the professional relationship between them. For example, in some cases, older Turkish adults assigned their children as their caregivers to help their offspring financially while they were not receiving any actual care in a way that they would receive from a professional caregiver. In addition, non-specialisation of family caregivers, e.g., not having been formally trained, decreased the quality of care received by some older Turkish adults.

Following family and relatives, neighbours had an important place in some older Turkish adults' web of social relations who could provide companionship and occasional instrumental support in the absence of family members. Although in Turkey, neighbourly relations, especially in villages and small cities, often formed strong support for older adults, many participants had not developed such close relationships with their Turkish neighbours in London. As the following quote indicates, for some participants, seeking help from neighbours was associated with burdensome feelings:

'My neighbours are mainly Turkish, but I cannot knock on their doors so often. I do not have such a personality to ask help from people ... These days, people are different. They do not care about each other.'

(Female, 63 years old, married, 20 years in London.)

In some cases, formal support was seen by participants as a prerequisite for healthy ageing, particularly when specific care needs emerged. People were concerned about shrinking informal support networks in old age, highlighting the importance of formal care in terms of healthy ageing:

'If there is somebody like a caregiver or your children to look after you in your old age, your life can become nice, but if there is no one around to help you, your life is hard.'

(Female, 56 years old, married, Mainland Turkey, 14 years in the UK.)

In the absence of informal support networks, some participants were using formal care services. Attitudes towards formal care were not favourable among the community, especially the older generation and those who arrived later to the UK with rural origins. Besides cultural acceptability of receiving formal care, other problems such as (un)affordability, insufficient care hours, and conflicts between caregivers and recipients were identified as some of the barriers to receiving adequate formal care among these participants.

\subsection{Individual Autonomy at Home and Choice in Housing Options}

The conceptualisation of independence among older Turkish adults encompassed aspects such as dignity and freedom that were bound in notions of 'home' at old age. Living in an institutional setting and receiving formal care for the majority of participants was considered as dependency on others and restricting personal freedom that undermined autonomy:

'I think the best option for an older adult is living in their own home, not nursing homes. Even if they own a room, they it will be more convenient there, because a human being in his own home feels more pride. It is more convenient. If you move to nursing home, you will feel bad. You will feel that you do not have anybody, but if you are in your own home, you are more comfortable, even when you make a cup of tea for yourself, it makes you happy.'

(Female, 60 years old, married, Mainland Turkey, 28 years in the UK.)

Satisfaction with housing and the living environment was recognised to be an indispensable part of healthy ageing and independence among many members of the Turkish community. Many factors were influential in participants' satisfaction of their home from ownership status to personal factors such as living alone or with family, levels of physical health, and environmental factors such as the physical and social environment of the neighbourhood, affordability, convenience, and safety. 
The majority of participants in this study were living in council housing. Inadequate housing, unaffordable rents, and landlords' decisions to terminate contracts were frequently reported problems experienced by tenant participants:

'I live in a house that is a private property, but the council has rented it. Landlord asks me to move out ... but it is his house there is nothing to do for that.'

(Female, 59 years old, living alone, Mainland Turkey, 13 years in the UK.)

Among our sample, socially rented participants had higher security in terms of length of the tenancy and affordability compared to private renters; however, the afore-mentioned problems in renting persisted. Middle-aged respondents (those aged between 50 and 55 years old), especially single participants, were more likely to report inadequate housing, or in extreme cases, homelessness. Relying on privately rented accommodation was more common among the younger generation of older Turkish adults.

Many older Turkish adults in our sample had negative experiences of housing associated with negative life course events such as homelessness, which lasted into old age. The majority of participants had relied on their family and friends for accommodation when initially arriving in the UK but had transitioned into their own accommodation over time:

'I was living with my son and daughter-in-law in Enfield, then I moved here. Of course, it is better to have your own home. I am satisfied living with my children, but they have little kids; we are now ageing, we want comfort.'

(Female, 57 years old, married, Cyprus, 12 years in the UK.)

For our sample, shared accommodation and intergenerational living arrangements were more common among newly arrived migrants (in the past 5 years) or families with economic hardship. Only in some cases was intergenerational living a personal choice among older Turkish adults. The majority of participants tried to avoid living with their children and grandchildren in the same house because of fear of being a burden on them, even if they had a desire for it. Living in a small flat close to their children's house was more common among participants.

In some cases, moving to a new house in old age, specifically, age-segregated housing such as sheltered housing or senior-specific apartments, was associated with feelings of loss, undermining dignity and autonomy in making personal decisions:

'... I spent a lot [of money] on my house. I do not want to leave it. I am used to my area. It is close to everywhere. Just the problems inside my house annoy me... They sent me a mail saying that I can move to a sheltered housing. I can never live there. I cannot move anywhere. It is for 27 years that I have been living here. Just for two times, our lift stopped working. Our view is very nice, too. I like everything about my house ... .'

(Female, 57 years old, 35 years in London, living alone, Mainland Turkey, community mapping workshop 4.)

However, for a number of participants, the absence of alternative accommodation was the main reason compelling them to age in their current home despite its inadequacy in terms of providing an environment to support healthy ageing and independence:

'It is a two-story house, not a flat. Bedroom and bathroom are upstairs. Kitchen and the living room downstairs. It is not possible for me to climb the stairs all the time to reach the bedroom for sleeping, so I sleep in my armchair. But I have a toilet downstairs. They made it for me. Like this ... i.e., I try to accept the conditions.'

(Female, 55 years old, living alone, Mainland Turkey, 26 years in the UK.)

\subsection{Functional Independence, Mobility, and Control over the Physical Environment}

\subsubsection{Inside Home Mobility}

Although the degree of one's fit with his/her home depends on physical capabilities and other personal factors, some architectural features of a home, such as stairs, are often considered as physical barriers to independence for the majority of older adults. Stairs 
inside the house were reported as significant barriers to independence, disrupting the daily life of participants and making them dependent on other people for completing their daily tasks, undermining their autonomy, independence, and dignity. The following quote from a female participant in her mid-50s illustrates how physical barriers at the home impact on sustaining activities of daily living (ADLs) and preserving dignity:

'It is a house. It has stairs inside. The doctor told me that I do not have to use stairs. Our stairs are very narrow and steep ... They put two handles on the sides of stairs. I use them to go up and down the stairs. As far as possible, I try to spend my time in my bedroom whenever there is not any necessary tasks to do downstairs. The toilet is upstairs. I have incontinence problem, too. I am not able to hold my toilet for a long time. Once, when I was going upstairs, I could not control myself.'

(Female, 56 years old, living alone, Mainland Turkey, 18 years in the UK.)

Exterior stairs were also repeatedly mentioned as a significant barrier to social participation and independence of older adults, weakening the connection of older adults with the out-of-home environment and disrupting independence by decreasing older adults' capabilities to perform out-of-home tasks such as shopping or accessing health care services. Difficulties in using the lift and being trapped inside the building were some of the common problems experienced by older adults living in high-rises. The following quote alludes to the links between barriers at home (in this case, exterior stairs) with negative feelings such as being trapped in the space and the increased dependency of older adults on other people to manage their daily life:

'I live in a 24-storey building. It is not a suitable place for ageing ... since Thursday both of our lifts have stopped working. They have not repaired them yet. I have a friend living on the 20th floor; I help her to climb the stairs until the 20th floor! It is a big frustration.

It is for days that we have been trapped there!'

(Female, 54 years old, married, Mainland Turkey 14 years in the UK.)

The other physical barrier to independence frequently mentioned by participants living in privately rented buildings or social housing was the old-styled bathrooms (heightened bathtubs) which made it difficult for older adults with mobility needs to use them. The following quote refers to some examples of difficulties experienced by participants in owning such kinds of bathrooms:

'My bathtub is very high; it is very hard to get into it and exit. My sons help me to get into it. It is for two years that I am waiting for them to come and modify it.'

(Female, 56 years old, living alone, Mainland Turkey, 18 years in the UK.)

Low levels of person-environment fit were closely related to socioeconomic status and demographic factors such as participants' age, gender, marital status, and education level. For example, female older adults living alone, with low financial security, were more likely to experience problems with home barriers such as stairs inside their house and in negotiating access to relevant institutions to resolve the issue.

The frequency of these problems was also more evident among participants with private tenancies. Investing money, time, and energy to make alterations in the home to adapt to occupants' needs to achieve person-environment fit is less feasible in rented accommodations, especially in the private-rented sector, which is usually shorter in duration and more restricted in terms of tenants' abilities to install home aids or physical adaptations.

Although not as intense as in the private sector, similar problems were observed among participants living in accommodations provided by the public sector, such as council and housing associations. These problems undermined their autonomy and independence. Professional service providers interviewed as part of this research also referred to the lack of housing options that can support wellbeing among older adults relying on the public sector for accommodation. The long bureaucratic process of applying to social housing, the time-consuming process of performing home repairs and installing housing aids, digitalisation, and older Turkish adults' lack of English language proficiency and IT 
skills were regarded as important barriers to healthy ageing by professional interviewees. The other factors contributing to the lack of social housing stock, mentioned by professional service providers for the community, were the increased number of immigrants with low financial security and a general economic downturn in the UK over recent decades.

\subsubsection{Out of Home Mobility}

The majority of participants, especially female older adults, were dependent on public transport or their children for mobility. This dependency was usually higher in low-density urban areas such as Enfield compared to high-density urban areas such as Edmonton Green due to lack of public transportation and connectivity in lower-density areas. Among interviewees, only a small number of participants owned a car and were able to drive. In addition, the use of public transport increased by age as older participants had lost their ability to walk long distances.

Among different public transportation modes, buses were the most common transport option used by participants because of the convenience of use and difficulties of finding one's way using the London Underground for participants with low or no English language skills. Lack of staff in underground tube stations to ask the address, a confusing passenger information system, and crowded stations were cited by many as not congruent with older adults' physical and mental capabilities. Participants with physical disabilities tended to avoid using trains because of high platforms at stops and the non-availability of lifts in some stations.

Walking short distances (as an alternative to public transport) in the neighbourhood was also a common mode of mobility among participants who were physically able and where the environment did not present barriers. However, in the majority of cases, fear of crime and previous experiences of being physically attacked and harassed hindered walking among participants. Fear of crime was more common among female participants living alone, especially after dark:

'There is always a fear in me when I walk, because for three times I have been attacked by thugs. Whenever I walk and feel that someone is walking behind me, I feel unsafe ... '

(Female, 70 years old, living alone, Mainland Turkey, 35 years in the UK.)

While buses were the preferred and the most frequently used mode of transport for the majority of participants, some interviewees encountered difficulties in using them. Over-crowding in the bus, unsheltered bus stops, and infrequent services on some lines, passenger's violation of priority seat rule, and the inconsiderate behaviour of some drivers who did not give enough information to passengers were some of the issues raised by participants that led to decreased use of bus services. The need for the use of English language skills was less mentioned as a requirement of the navigation of bus services by participants. However, as the quote below indicates, lack of adequate information about bus routes in languages other than English is a deficiency of the public transportation system, restricting some participants' mobility:

'I do not know English to ask the address from driver. I only get on the bus and go ... but I have learned the route to my sister's house. In the past, I used to lose my way when I was trying to reach to her house, but after 1-2 times, I learned it ...'

(Female, 83 years old, living alone, Mainland Turkey.)

Holding classes for older adults with lower levels of English proficiency level and providing information on the use of public transportation was one of the key identified needs among the interviewees to facilitate independence and healthy ageing. Here, education was strongly linked to the ability to move around and therefore mastery of the built environment:

'Many of the older adults that come here are illiterate, they cannot read, so they cannot take the bus alone to come here. If there were some education classes for them to teach the routes, it would become nice.' 


\section{(Female, 55 years old, 15 years in the UK.)}

The quotes above allude to the importance of education and control in designing supports for older people. Lack of English language proficiency along with lack of knowledge of necessary transportation information such as schedules and stops were regarded as major restrictive factors for older Turkish adults' independence:

'Language is a big problem, really. Besides, they are not familiar with the system. Because of these two problems they are very dependent on their children...'

(General Secretary of a religious and cultural association, Male.)

The perceived failure of the public transportations to meet age-friendly design criteria was mentioned as a deterrent undermining older adults' propensity to healthy ageing and independence. Lack of coverage in the public transportation network, non-inclusive design of transport modes and stops, and the complexity and lack of an age-friendly information system for public transport users were some of the aspects adversely impacting mobility. In relation to the lack of an age-friendly public transportation system, some professionals referred to the importance of the provision of drop-off services specific to older adults visiting associations to encourage social participation, enhance mental wellbeing, and decrease their dependency on others:

'Now, they are coming with the help of their children or relatives. But to call somebody every time that they want to come here and asking them is devastating both from psychological and time aspects (they cannot be here on time). Availability of a pick-up and drop-off service is very important to enable them to spend at least two hours here daily...'

(General Coordinator of a religious and cultural association, Male.)

In the absence of an effective public transportation system for older adults, some participants had to rely on private modes such as mini-cabs and taxies for mobility despite the high costs of using the services, which participants could hardly afford. The lack of discounts for older adults in using these services was mentioned by a female participant as a barrier to mobility independence and social participation:

'I think there should be discounts on mini-cabs for us ... we cannot access everywhere by bus. For example, when I go to a restaurant with my friends, I have to leave the place before 8 p.m. to not be compelled to use a mini-cab. Mini-cabs are very expensive ... When we go outside at night, when it comes to returning home, all of us are stressed. We cannot afford mini-cabs all the time...'

(Female, 57 years old, living alone, Mainland Turkey, 35 years in the UK, community mapping workshop 4.)

\section{Discussion}

The findings of this study illustrate the complexity in the conceptualisation and experiences of independence among older Turkish adults in the UK. Such complexities are associated with more generic aspects of ageing - such as availability of care services and how well the environment fits the needs of older people-as well as specific elements for this group, including their migration trajectories, perceived family relations, and community values. Traditional Anatolian culture is based on Islamic filial piety, in which support and sacrifices of parents towards their children, and the obedience and responsibility of children in caring for their parents in old age, were widely accepted strong values [48]. In this cultural context, caregiving to older adults is generally regarded as the younger family members' obligation, usually fulfilled by female members of the family such as daughters or daughters-in-law. This attitude towards care has been influenced by the reinterpretation of traditional norms and the acceptance of new norms through the diffusion of ideas in recent decades both in Turkey [49] and among the Turkish community in London.

The analysis highlights that interdependency, rather than dependency, was dominant, albeit with varied definitions and interpretations, among the various groups of the Turkish community in London. The perceived inability of older Turkish migrants to reciprocate the 
help received from children and other kin was associated with feelings of being a burden. In the narratives of older Turkish migrants, the emphasis on functional dependency did not seem to necessarily resonate with the same meaning employed in the literature focused on western older adults in terms of 'not accepting help from others' or 'performing activities alone' $[50,51]$, it was more about concerns over being an excessive burden on children or not requesting help even when needed $[14,29,52]$.

Lack of English language proficiency and unfamiliarity with the UK rules and regulations were recognised as important barriers to independence amongst most participants. In the absence of personal resources, material resources such as housing and finance were utilised in maintaining a reciprocal relationship with support networks such as exchange of money in the care received by family members or having a separate house from married children. However, not all older Turkish adults have sufficient resources to reciprocate the instrumental support received from other family and kin members. In addition, the family was not always available to provide care and support in old age, or in some cases, provide inadequate support, a situation highlighted in previous research [53]. This shows the importance of 'outside of kin' support for older Turkish adults, such as that delivered through governmental institutions or charitable organisations.

One of the most important resources that respondents drew on to maintain independence was the notion of home. The home was an indispensable part of participants' accounts of independence and healthy ageing, enabling or disabling access to everyday supports. The ownership status of a home is also recognised to be an important factor in an individual's control and autonomy by providing a 'private place away from the uncertainty of public life' [54] (p. 3). Renting has been recognised as a less secure tenure type in the academic literature, decreasing the sense of control [55], identity and belonging [56], and overall mental wellbeing [57]. A significant number of older adults in the UK rent their properties through the private or public sectors [58]. Although official figures around the number of ethnic minority older adults renting properties are not available, the results of a previous study conducted on the Turkish community reveal that the majority of the community relies on social housing [59].

The home was also identified as an important part of older Turkish adults' identity and social life, as a place of interaction with immediate family members or meeting other people in the social network such as neighbours or relatives [60], since most of the interactions with social networks was happening inside the home rather than in urban spaces, especially for older female Turkish adults. The internalisation of an image of a self-reliant older adult among participants had resulted in the desire to have a separate residential arrangement from adult children (voluntarily or involuntarily in some cases). However, receiving social and emotional support and the need for frequent visits from children and grandchildren were perceived as crucial to older Turkish adults' wellbeing. This emotional and sometimes practical dependency on children has translated into physical proximity, with many living in the same neighbourhood as their children. In other words, the physical space of the home was regarded as a medium through which older Turkish adults negotiated independence with their social networks remaining close by. A previous UK study focusing on Welsh older adults indicates the important role of home in creating a sense of independence and privacy by having one's own space and deciding who can visit and when [61]. In contrast, in our study, although having better privacy was a motivation to opt for living alone in some older Turkish people; burdensome feelings and fears of being imposed on their children and in-laws were the main motivation for the majority of participants to have a separate residential arrangement.

Mobility played an important role in participants' conceptualisation of independence. Several studies similarly confirm the association between physical mobility, both inside and outside of the home, with an increased sense of independence, autonomy, and control amongst older adults $[29,62]$. In some literature, the term mobility has been used interchangeably with independence in terms of having a mobile body that is able to achieve 
things by itself [63]. In this study, the lack of access to transport and poor physical health were recognised as factors restricting older Turkish adults' mobility and independence.

Results of the interviews showed that mobility outside of the home for older Turkish adults was strongly impacted by language skills. Lack of English language skills led to feelings of being unsafe in urban spaces, reduced control, and mastery over the environment, thus restricting mobility to the home domain. Lack of individual mobility options and reliance on public transportation was the case for the majority of participants where public transportation was not supportive of older Turkish adults' language and cultural needs combined with declining physical capabilities. Lack of information in other languages than English and lack of trained drivers regarding behaviour with older adults were identified as factors restricting participants' willingness to use public transportation. Physical barriers in access and lack of age-friendly design considerations, both in bus stops/stations and vehicles, were also mentioned as factors restricting older adults' ability to use public transportation, increasing their dependency on family members for out-of-home mobility.

For many participants, especially female respondents, mobility inside the home was recognised to be the main factor in facilitating functional independence. Physical and architectural features of the home were important in facilitating or hindering older adults' freedom of mobility inside the house and performing daily tasks. Several studies similarly support the association between the physical structure and design of a house with the mobility of older adults inside their house, e.g., [64,65]. Ownership status in our study was recognised as an important factor in the degree of fit between participants and their homes. The majority of respondents resided in social housing units with certain architectural features that restricted their mobility and independence inside the house. However, they were not able to make the desired physical changes in their home for various reasons, such as financial constraints, landlord's resistance, and institutional barriers.

The findings highlight the multiple dimensions of independence, such as dignity, choice, and control over the physical and social environment. Older Turkish migrants in the UK value achieving healthy ageing rather than merely physical health and functional independence endorsed by successful ageing models. Results of this research indicate a lack of control over the environment and relationships amongst older Turkish adults in London because of the combined effects of ageing and migration. Changing relations within social networks force older Turkish adults to navigate the services and environments independently where these resources do not accommodate for their linguistic and cultural requirements. Older Turkish adults in the UK displayed lower levels of choice in terms of access to culturally competent and affordable formal care services, housing, and transportation options compromising dignity and freedom, further hindering their ability to ensure healthy ageing. Therefore, more diverse understandings of the notion of healthy ageing need to prioritised within housing and care interventions, including those concerning the transportation sector, and other policy spheres concerned with older adults wellbeing so they are able to respond to how healthy ageing is experienced in the daily lives of older adults from diverse backgrounds.

\section{Conclusions}

Analysing independence as the main component of healthy ageing showed its contingency on several social, spatial, and cultural factors. The lived experiences of older Turkish migrants in the UK revealed a complex interaction of various personal and community factors, such as ethnicity, socioeconomic position, gender, income, social networks, living arrangements, and access to services, to shape an individual's capacity for independence and harnessing healthy ageing opportunities. Ignoring the nuances in which healthy ageing is experienced and perceived adversely impacts the uptake of various policies that do not directly address and provide means to ensuring sustainable and equitable ageing opportunities and mechanisms across the diverse groups of the older UK population. 
Author Contributions: M.Y.: Conceptualisation, methodology, formal analysis, writing, and original draft preparation, editing; S.H.: support during fieldwork and with analysis, writing, reviewing, editing, and supervision. Both authors have read and agreed to the published version of the manuscript.

Funding: This research was partially supported by the School of Energy, Geoscience, Infrastructure and Society, James-Watt Scholarship 2015/16, Heriot-Watt University, which funded M.Y.'s PhD.

Institutional Review Board Statement: The study was conducted according to the guidelines of the Declaration of Helsinki, and approved by the Research Ethics Committee of School of Energy, Geoscience, Infrastructure and Society at Heriot-Watt University available at: https: / /www.hw.ac. uk/documents/research-ethics-policy.pdf (date of approval: 02/05/2016).

Informed Consent Statement: Informed consent was obtained from all subjects involved in the study.

Acknowledgments: This article is based on M.Y.'s Ph.D. thesis at Heriot-Watt University. We would like to thank Ryan Woolrych and Gina Netto for their guidance and supervision during this project.

Conflicts of Interest: The authors declare no conflict of interest.

\section{References}

1. United Nations, Department of Economic and Social Affairs [UNDESA], Population Division. World Population Ageing 2019: Highlights (ST/ESA/SER.A/430). 2019. Available online: https://www.un.org/en/development/desa/population/ publications/pdf/ageing/WorldPopulationAgeing2019-Highlights.pdf (accessed on 1 August 2021).

2. Martin, R.; Williams, C.; O'Neill, D. Retrospective analysis of attitudes to ageing in the Economist: Apocalyptic demography for opinion formers. BMJ 2009, 339, b4914. [CrossRef]

3. Gee, E.; Gutman, G. The Overselling of Population Ageing: Apocalyptic Demography, Intergenerational Challenges, and Social Policy; Oxford University Press: Oxford, UK, 2000.

4. Foster, L.; Walker, A. Active and Successful Aging: A European Policy Perspective. Gerontologist 2015, 55, 83-90. [CrossRef]

5. Davey, J.; Glasgow, K. Positive ageing: A critical analysis. Policy Q. 2006, 2, 21-27, . [CrossRef]

6. Bowling, A. Ageing Well: Quality of Life in Old Age; Open University Press: London UK, 2005.

7. Fernandez-Ballesteros, R. Positive ageing: Objective, subjective, and combined outcomes. E-J. Appl. Psychol. 2011, 7, 22-30. [CrossRef]

8. United Nations. Decade of Healthy Ageing 2020-2030. 2020. Available online: https://cdn.who.int/media/docs/default-source/ decade-of-healthy-ageing / final-decade-proposal /decade-proposal-final-apr2020-en.pdf?sfvrsn=b4b75ebc_25\&download= true (accessed on 17 July 2021).

9. Peel, N.; Bartlett, H.; McClure, R. Healthy ageing: How is it defined and measured? Australas. J. Ageing 2004, 23, 115-119. [CrossRef]

10. McLaughlin, S.J.; Jette, A.M.; Connell, C.M. An Examination of Healthy Aging across a Conceptual Continuum: Prevalence Estimates, Demographic Patterns, and Validity. J. Gerontol. Ser. A Boil. Sci. Med. Sci. 2012, 67, 783-789. [CrossRef]

11. Burke, G.L.; Arnold, A.M.; Bild, D.E.; Cushman, M.; Fried, L.P.; Newman, A.; Nunn, C.; Robbins, J.; The CHS Collaborative Research Group. Factors Associated with Healthy Aging: The Cardiovascular Health Study. J. Am. Geriatr. Soc. 2001, 49, 254-262. [CrossRef]

12. Rudnicka, E.; Napierała, P.; Podfigurna, A.; Męczekalski, B.; Smolarczyk, R.; Grymowicz, M. The World Health Organization (WHO) approach to healthy ageing. Maturitas 2020, 139, 6-11. [CrossRef]

13. Lowry, K.A.; Vallejo, A.N.; Studenski, S.A. Successful Aging as a Continuum of Functional Independence: Lessons from Physical Disability Models of Aging. Aging Dis. 2012, 3, 5-15.

14. Allam, A. The Meaning of Independence for Older People: A Constructivist Grounded Theory Study. Ph.D. Thesis, University of York, York, UK, 2015. Available online: https: / / etheses.whiterose.ac.uk/12407/ (accessed on 14 March 2019).

15. Stone, S.D. Disability, Dependence, and Old Age: Problematic Constructions. Can. J. Aging Rev. Can. Vieil. 2003, 22, 59-67. [CrossRef]

16. Rubinstein, R.L.; de Medeiros, K. "Successful Aging," Gerontological Theory and Neoliberalism: A Qualitative Critique. Gerontologist 2015, 55, 34-42. [CrossRef] [PubMed]

17. Angus, J.; Reeve, P. Ageism: A Threat to "Aging Well" in the 21st Century. J. Appl. Gerontol. 2006, 25, 137-152. [CrossRef]

18. King, N.; Calasanti, T.; Pietilä, I.; Ojala, H. The Hegemony in Masculinity. Men Masc. 2021, 24, 432-450. [CrossRef]

19. Timonen, V. Beyond Successful and Active Ageing: A Theory of Model Ageing; Policy Press: Bristol, UK, 2016.

20. Rozanova, J.; Keating, N.; Eales, J. Unequal social engagement for older adults: Constraints on choice. Can. J. Aging 2012, 31, 25-36. [CrossRef]

21. Agich, G. Dependence and Autonomy in Old Age: An Ethical Framework for Long-Term Care; Cambridge University Press: Cambridge, UK, 2003. [CrossRef]

22. Stephens, C.; Breheny, M. Healthy Ageing: A Capability Approach to Inclusive Policy and Practice; Routledge: Oxon, UK, 2019. 
23. Dillaway, H.E.; Byrnes, M. Reconsidering Successful Aging: A Call for Renewed and Expanded Academic Critiques and Conceptualizations. J. Appl. Gerontol. 2009, 28, 702-722. [CrossRef]

24. Martinson, M.; Berridge, C. Successful Aging and Its Discontents: A Systematic Review of the Social Gerontology Literature. Gerontologist 2014, 55, 58-69. [CrossRef]

25. Noppert, G.A.; Brown, C.S.; Chanti-Ketterl, M.; Hall, K.S.; Newby, L.K.; Cohen, H.J.; Morey, M.C. The Impact of Multiple Dimensions of Socioeconomic Status on Physical Functioning Across the Life Course. Gerontol. Geriatr. Med. 2018, 4, 2333721418794021. [CrossRef]

26. WHO. World Report on Ageing and Health. World Health Organization. 2015. Available online: https://www.who.int/ageing/ publications/world-report-2015/en/ (accessed on 14 October 2018).

27. Rabiee, P. Exploring the Relationships between Choice and Independence: Experiences of Disabled and Older People. Br. J. Soc. Work. 2012, 43, 872-888. [CrossRef]

28. Feingold, E.; Werby, E. Supporting the Independence of Elderly Residents through Control Over Their Environment. J. Hous. Elder. 1990, 6, 25-32. [CrossRef]

29. Parry, J.; Vegeris, S.; Hudson, M.; Barnes, H.; Taylor, R. Independent Living in Later Life. Research Report 216; Department for Work and Pensions: Leeds, UK, 2004; Available online: https://lemosandcrane.co.uk/resources/DWP\%20-\%20Independent\%20 living\%20in\%20later\%20life.pdf (accessed on 29 July 2020).

30. Fenton, S.J. Ageing and Agency: The Contested Gerontological Landscape of Control, Security and Independence and the Need for Ongoing Care and Support; Birmingham Policy Commission: Birmingham, UK, 2014; Available online: https:/ /www.birmingham.ac.uk/ Documents / research/policycommission/healthy-ageing/5-Ageing-and-agency-control-and-independence-updated.pdf (accessed on 13 May 2019).

31. De Tavernier, W.; Aartsen, M. Old-Age Exclusion: Active Ageing, Ageism and Agency. Soc. Incl. 2019, 7, 3. [CrossRef]

32. Scharf, T.; Shaw, C.; Bamford, S.-M.; Beach, B.; Hochlaf, D. Inequalities in Later Life; Center for Ageing Better: London, UK, 2017; Available online: https:/ / www.ageing-better.org.uk/sites/default/files/2017-12/Inequalities\%20scoping\%20review\%20full\% 20report.pdf (accessed on 11 May 2019).

33. De Noronha, N. Housing and the Older Ethnic Minority Population in England; Race Equality Foundation: London, UK, 2019; Available online: https://www.housinglin.org.uk/_assets/Resources/Housing/Supportwr_materials/Briefings/HLIN_Briefing_ BME_Housing.pdf (accessed on 29 July 2020).

34. Ali, P.A.; Watson, R. Language barriers and their impact on provision of care to patients with limited English proficiency: Nurses' perspectives. J. Clin. Nurs. 2018, 27, e1152-e1160. [CrossRef] [PubMed]

35. Cylwik, H. Expectations of Inter-Generational Reciprocity among Older Greek Cypriot Migrants in London. Ageing Soc. 2002, 22, 599-613. [CrossRef]

36. Caner, A.; Pedersen, P.J. Does Poverty Among Immigrants Adapt to Country of Residence? Turks in Germany and Denmark. Int. Migr. 2019, 57, 264-280. [CrossRef]

37. Hussein, S. Ageing Turkish Migrants in European Cities Experience Worrying Levels of Social Isolation Which Can Limit Their Access to Health and Social Care Services. European Politics and Policy Blog. 2013. Available online: https://blogs.lse.ac.uk/ europpblog/2013/02/18/ageing-turkish-migrants-london-europe (accessed on 27 July 2020).

38. Hussein, S.; Öglak, S. Older Turkish migrants in the UK: Role of distinct culture, immigration histories and unmet care needs. In Proceedings of the Turkish Migration in Europe Conference, Regent's College London, London, UK, 7-9 December 2012; Available online: https://www.kcl.ac.uk/scwru/pubs/2012/conf/husseinoglak8dec12.pdf (accessed on 20 August 2021).

39. Topal, K.; Eser, E.; Sanberk, I.; Bayliss, E.; Saatci, E. Challenges in access to health services and its impact on quality of life: A randomised population-based survey within Turkish speaking immigrants in London. Health Qual. Life Outcomes 2012, 10, 11. [CrossRef]

40. Clifford, N.; Cope, M.; Gillespie, T.; French, S. Key Methods in Geography; SAGE Publications: California, USA, 2016.

41. Burns, J.; Paul, D.; Paz, S. Participatory Asset Mapping. 2012. Available online: https://www.communityscience.com/ knowledge4equity/AssetMappingToolkit.pdf (accessed on 11 May 2016).

42. Ayalon, L.; Levkovich, I. A Systematic Review of Research on Social Networks of Older Adults. Gerontologist 2019, 59, e164-e176. [CrossRef]

43. Notthoff, N.; Reisch, P.; Gerstorf, D. Individual Characteristics and Physical Activity in Older Adults: A Systematic Review. Gerontology 2017, 63, 443-459. [CrossRef] [PubMed]

44. McConatha, J.T.; Hayta, V.; Rieser-Danner, L.; McConatha, D.; Polat, T.S. Turkish and U.S. Attitudes toward Aging. Educ. Gerontol. 2004, 30, 169-183. [CrossRef]

45. Greater London Authority. Turkish, Kurdish and Turkish Cypriot Communities in London; Greater London Authority: London, UK, 2009; Available online: https://csdinternationalcommunityproject.files.wordpress.com/2012/03/turkish-communities6.pdf (accessed on 10 September 2021).

46. Braun, V.; Clarke, V. Using thematic analysis in psychology. Qual. Res. Psychol. 2006, 3, 77-101. [CrossRef]

47. Vaismoradi, M.; Turunen, H.; Bondas, T. Content analysis and thematic analysis: Implications for conducting a qualitative descriptive study. Nurs. Health Sci. 2013, 15, 398-405. [CrossRef]

48. Imamoğlu, E.O. An interdependence model of human development. In Growth and Progress in Cross-Cultural Psychology; Swets North America: Berwyn, PA, USA, 1987; pp. 138-145. 
49. Smith, M.B. Perspectives on Human Development, Family, and Culture; Bekman, S., Aksu-Koç, A., Eds.; Cambridge University Press: Cambridge, UK, 2009.

50. Portacolone, E. The Myth of Independence for Older Americans Living Alone in the Bay Area of San Francisco: A Critical Reflection. Ageing Soc. 2011, 31, 803-828. [CrossRef]

51. Plath, D. International policy perspectives on independence in old age. J. Aging Soc. Policy 2009, 21, 209-223. [CrossRef]

52. Cahill, E.; Lewis, L.M.; Barg, F.K.; Bogner, H.R. "You don't want to burden them.": Older adults' views on family involvement in care. J. Fam. Nurs. 2009, 15, 295-317. [CrossRef] [PubMed]

53. Hussein, S. Migration Gender and Social Inclusion. In Ageing, Diversity and Inequality: Social Justice Perspectives; Westwood, S., Ed.; Routledge: London, UK, 2020; pp. 181-193.

54. Bate, B. Understanding the influence tenure has on meanings of home and homemaking practices. Geogr. Compass 2018, 12, e12354. [CrossRef]

55. Manturuk, K.R. Urban Homeownership and Mental Health: Mediating Effect of Perceived Sense of Control. City Community 2012, 11, 409-430. [CrossRef]

56. Holdsworth, L. Just renting: Implications of renting on community, place and identity: An empirical inquiry. In Proceedings of the Community, Place, Change. The Annual Conference of the Australian Sociological Association (TASA), Sandy Bay, Hobart, Australia, 5-8 December 2005.

57. Luginaah, I.; Arku, G.; Baiden, P. Housing and health in Ghana: The psychosocial impacts of renting a home. Int. J. Environ. Res. Public Health 2010, 7, 528-545. [CrossRef]

58. Age UK. Ageing in Squalor and Distress: Older People in the Private Rented Sector. Older People Who Privately Rent their Homes; Age UK: London, UK, 2016; Available online: https://www.ageuk.org.uk/globalassets/age-uk/documents/reports-and-publications / reports-and-briefings/safe-at-home/rb_oct16_ageing_in_squalor_and_distress_report.pdf (accessed on 15 August 2021).

59. D'Angelo, A.; Galip, O.; Kaye, N. Welfare needs of Turkish and Kurdish communities in London: A community based research project. 2013. Available online: http://sprc.info/wp-content/uploads/2013/07/DayMer-Final-Report-final.pdf. (accessed on 12 June 2019).

60. Sixsmith, A.; Sixsmith, J. Ageing in place in the United Kingdom. Ageing Int. 2008, 32, 219-235. [CrossRef]

61. Hillcoat-Nallétamby, S. The meaning of „independence” for older people in different residential settings. J. Gerontology. Ser. B Psychol. Sci. Soc. Sci. 2014, 69, 419-430. [CrossRef] [PubMed]

62. Webber, S.C.; Porter, M.M.; Menec, V.H. Mobility in older adults: A comprehensive framework. Gerontologist 2010, 50, 443-450. [CrossRef]

63. Gabriel, Z.; Bowling, A. Quality of life from the perspectives of older people. Ageing Soc. 2004, 24, 675-691. [CrossRef]

64. National Research Council, The Role of Human Factors in Home Health Care; National Academies Press: Washington, DC, USA, 2010.

65. Hwang, E.; Cummings, L.; Sixsmith, A.; Sixsmith, J. Impacts of Home Modifications on Aging-in-Place. J. Hous. Elder. 2011, 25, 246-257. [CrossRef] 